\title{
IMEC-15 to be held in Israel in 2012
} www.imec.org.il

$\mathbf{T}$ he 15th Israel Materials Engineering Conference (IMEC-15) will be held at the Le Meridien Hotel at the Dead Sea, Israel, on February 28-March 1,2012 . The conference is chaired by Guy Makov of Ben-Gurion University of the Negev. The conference is endorsed by the Materials Research Society, with sponsors including the European Materials Research Society.

Spanning both fundamental and applied research, IMEC-15 plans to reflect the recent breakthroughs in a range of topics, including nanomaterials, biomaterials, materials for energy systems and cleantech, and advanced characterization techniques. Plenary presentations will be given by internationally renowned scientists together with keynote talks by leading scientists from Israel and abroad. Invited speakers include Sir Richard Friend (Cambridge University, UK), Nicola Marzari (University of Trieste, Italy), Eduard Arzt (Leibniz Institute for New Materials in Saarbrücken, Germany), and Joanna Aizenberg (Harvard University, USA). The conference will also include specialized topical sessions, poster sessions, a commercial exhibition, and a conference dinner. Awards will be given to the best student presentations.

The broad coverage by IMEC-15 should provide scientific interest and stimulation to the materials science and engineering community, as well as to a wide interdisciplinary audience including chemists, physicists, and engineers in related fields. The aim of the conference is to bring together academia, research institutes, industry, non-government organizations, and government representatives to exchange information, consolidate and initiate joint research programs, and discuss new opportunities.

The abstract submission deadline is December 2, 2011.

Additional information and registration details are available at www.imec org.il, or by contacting the conference secretariat at Diesenhaus Unitours Incoming Tourism Ltd., Conventions Department 3 Hamelacha St., P.O. Box 57176, Tel-Aviv 61571, Israel; tel. 972-3-5651324; fax 972-3-5610152; or e-mail IMEC15@diesenhaus.com.

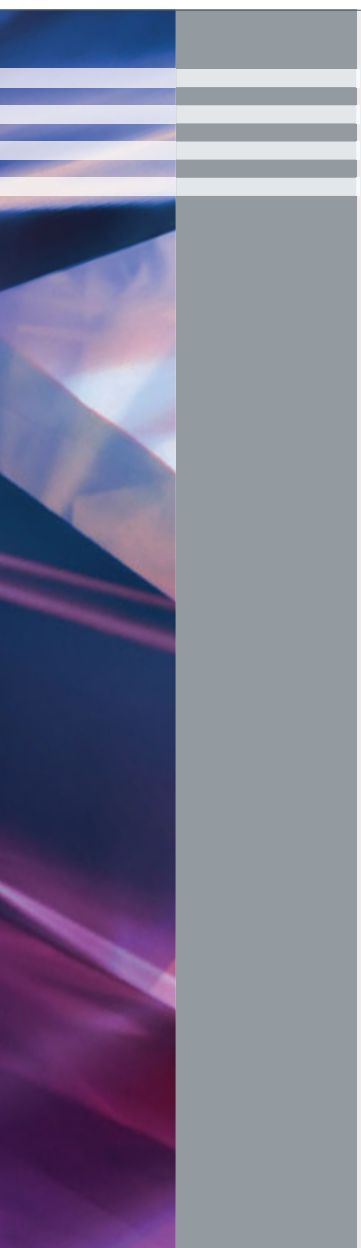

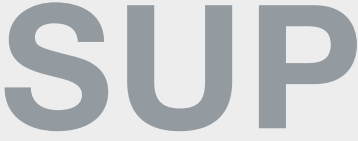
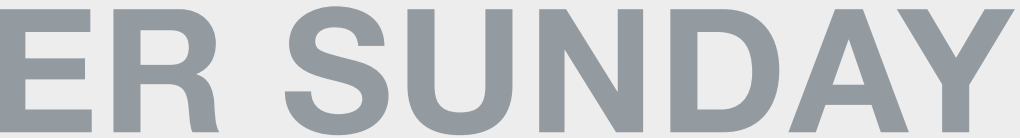

Don't miss these SUPER SUNDAY events at the 2011 MRS Fall Meeting · November 27 - All FREE to Meeting Attendees

\section{TUTORIAL SESSIONS}

Running throughout the day, the tutorials offer a variety of topics to complement the scientific sessions.

Subjects range from organic photovoltaics, to ferroelectric and multiferroic materials, to 3D imaging of materials microstructures in different length scales, and so much more!

\section{ACTA MATERIALIA MATERIALS AND SOCIETY AWARD FORUM - VEHICLE ELECTRIFICATION}

This forum will address the key technology areas required for vehicle electrification and explore the critical materials issues in each area. Developing the required materials solutions will be crucial to realizing the promise of electric vehicles and providing significant energy, environmental, and economic benefits to society.

\section{PROFESSIONAL DEVELOPMENT WORKSHOPS}

- Mastering Science Presentations

Learn how to choose the very best communication tools to take your scientific presentations to the next level-

and to successfully communicate the results both to peers and to the general public.

- Making the Most Out of Broadcast Media

Learn how to publicize your research in the media, including how to craft a newsworthy message, and how to best prepare for and execute a media interview.

- Effective Time Management for the New Millennium (additional advance registration required) Regain control of your time, including your e-mail inbox! Whether this is your first time-management workshop, or a refresher course, you will learn how to achieve more at work and in your personal time.

- Careers in Academia (additional advance registration required)

Planning a career in academia? Gain insight into the application process, learn how to prepare a competitive faculty application, and receive feedback on your CV. The event will include instructor-led presentations, trial interviews, and practice on your 3-minute "elevator speech."

FRED KAVLI DISTINGUISHED LECTURESHIP IN NANOSCIENCE

World-renowned scientist, Mark Davis, California Institute of Technology, will present his Kavli lecture at 7PM in the Sheraton Hotel, Grand Ballroom.

For more information on SUPER SUNDAY events, visit www.mrs.org/f11-supersunday 